\title{
Electrical stimulation-evoked contractions blunt orthostatic hypotension in sub-acute spinal cord-injured individuals: two clinical case studies
}

\author{
NA Hamzaid ${ }^{1}$, LT Tean ${ }^{1}$, GM Davis ${ }^{1,2}$, A Suhaimi $^{3}$ and N Hasnan ${ }^{3}$
}

Study design: Prospective study of two cases.

Objectives: To describe the effects of electrical stimulation (ES) therapy in the 4-week management of two sub-acute spinal cordinjured (SCI) individuals (C7 American Spinal Injury Association Impairment Scale (AIS) B and T9 AIS (B)).

Setting: University Malaya Medical Centre, Kuala Lumpur, Malaysia.

Methods: A diagnostic tilt-table test was conducted to confirm the presence of orthostatic hypotension $(\mathrm{OH})$ based on the current clinical definitions. Following initial assessment, subjects underwent 4 weeks of ES therapy 4 times weekly for $1 \mathrm{~h}$ per day. Post-tests tilt table challenge, both with and without ES on their rectus abdominis, quadriceps, hamstrings and gastrocnemius muscles, was conducted at the end of the study (week 5). Subjects' blood pressures (BP) and heart rates (HR) were recorded every minute during pretest and post-tests. Orthostatic symptoms, as well as the maximum tolerance time that the subjects could withstand head up tilt at $60^{\circ}$, were recorded.

Results: Subject A improved his orthostatic symptoms, but did not recover from clinically defined $\mathrm{OH}$ based on the 20-min duration requirement. With concurrent $\mathrm{ES}$ therapy, $60^{\circ}$ head up tilt $\mathrm{BP}$ was $89 / 62 \mathrm{~mm} \mathrm{Hg}$ compared with baseline $\mathrm{BP}$ of $115 / 71 \mathrm{~mm} \mathrm{Hg}$. Subject B fully recovered from $\mathrm{OH}$ demonstrated by BP of $105 / 71 \mathrm{~mm} \mathrm{Hg}$ during the $60^{\circ}$ head up tilt compared with baseline BP of $124 / 77 \mathrm{~mm} \mathrm{Hg}$. Both patients demonstrated longer tolerance time during head up tilt with concomitant ES (subject A: pre-test 4 min, post-test without ES 6 min, post-test with ES 12 min; subject B: pre-test 4 min, post-test without ES 28 min, post-test with ES 60 min). Conclusions: Weekly ES therapy had positive effect on $\mathrm{OH}$ management in sub-acute $\mathrm{SCl}$ individuals.

Spinal Cord (2015) 53, 375-379; doi:10.1038/sc.2014.187; published online 4 November 2014

\section{INTRODUCTION}

Autonomic control of systemic blood pressure (BP) is multi-factorial, ${ }^{1}$ but primarily operates through regulation of cardiac output and systemic vascular resistance. Orthostatic hypotension $(\mathrm{OH})$ is common among spinal cord-injured (SCI) individuals ${ }^{2}$ due to loss of function in their autonomic nervous system, affecting reduced regulation of vascular resistance below the spinal lesion and diminished stroke volume. ${ }^{3}$ The American Autonomic Society and American Academy of Neurology has defined $\mathrm{OH}$ as a decrease in systolic BP (SBP) of at least $20 \mathrm{~mm} \mathrm{Hg}$ or a decrease in diastolic BP (DBP) of minimum $10 \mathrm{~mm} \mathrm{Hg}$ during $20 \mathrm{~min}$ of head up tilt at $60^{\circ}$. Illman et al. noted, in their study on acute SCI patients, that $74 \%$ of the subjects experienced clinical manifestations of $\mathrm{OH}$. Nearly $50 \%$ of the subjects discontinued their treatment due to overwhelming $\mathrm{OH}$ symptoms. Some authors have also noted that $\mathrm{OH}$ may occur with or without any symptoms. ${ }^{2,4}$

Sub-acute SCI individuals may experience symptoms of $\mathrm{OH}$ such as dizziness, affected vision, exhaustion, pain, syncope, pallor and eventually fainting. $\mathrm{OH}$ can be provoked by altering body position from supine posture to upright status. $\mathrm{OH}$ is diminished when the body position is tilted back to supine position. The magnitude of $\mathrm{BP}$ decreases, the rate at which the patient's BP decline and poor cerebral autoregulation all can elicit symptoms of $\mathrm{OH}$.

Pathophysiological explanations for $\mathrm{OH}$ in SCI include loss of skeletal muscle pumping activity and reduced venous return when in transferred to upright postures, leading to a lowered stroke volumes, reduced cardiac outputs and blunted BPs with a net reduction of cerebral blood flow. ${ }^{5}$ In the upright position, venous blood accumulates in the lower extremities, such as legs and thoraco-abdominal vascular beds. SCI patients with their reduced skeletal muscle pump due to muscle paralysis/paresis are more predisposed to 'circulatory hypokinesis' during upright postures. Raymond et al. ${ }^{6}$ demonstrated that peripheral resistance, cardiac output, heart rate (HR) and stroke volume were increased when rhythmic leg muscle contractions were induced by neuromuscular electrical stimulation (ES).

Several studies have deployed ES for management of BPs in SCI patients during a head up orthostatic challenge, ${ }^{7-10}$ as well as during stationary and dynamic stance. ${ }^{11}$ Although the effect of ES on autonomic control after SCI is unclear, BP is better maintained under head up tilt due to reduced diminution of stroke volume. ${ }^{12}$ Previous

${ }^{1}$ Department of Biomedical Engineering, Faculty of Engineering, University of Malaya, Kuala Lumpur, Malaysia; ${ }^{2}$ Discipline of Exercise and Sport Science, Faculty of Health Sciences, University of Sydney, Sydney, New South Wales, Australia and ${ }^{3}$ Department of Rehabilitation Medicine, Faculty of Medicine, University of Malaya, Kuala Lumpur, Malaysia

Correspondence: Dr NA Hamzaid, Department of Biomedical Engineering, Faculty of Engineering, University of Malaya, Kuala Lumpur 50603, Malaysia.

E-mail: azah.hamzaid@um.edu.my

Received 9 January 2014; revised 25 July 2014; accepted 29 September 2014; published online 4 November 2014 
investigations have also shown that HR increased when ES was applied to persons with $\mathrm{SCI},{ }^{13}$ including during head-up tilt with concomitant ES. ${ }^{8,9,14}$

From a survey of the literature, the authors were unable to document a previous study that investigated the outcomes of ES therapy as a weekly training regimen in managing $\mathrm{OH}$ in sub-acute SCI patients, especially for maintaining their BP and the HR during orthostatic challenge. This study was a pilot investigation to explore responses to regular ES therapy before undertaking a larger trial. We sought to investigate the potential improvement of $\mathrm{OH}$ through a structured weekly ES training regimen.

\section{MATERIALS AND METHODS}

\section{Study participants}

SCI patients were recruited from the Rehabilitation Ward in UMMC (University Malaya Medical Centre). Subject inclusion criteria were aged between 18 and 65 years, newly diagnosed SCI the subacute phase, had BP changes during a modified orthostatic test by modified tilt table challenge test protocol by Czell, ${ }^{15}$ had $\mathrm{OH}$ diagnostic criteria according to the American Autonomic Society and American Association of Neurology, ${ }^{16}$ able to understand instructions, respond and provide consent and able to participate in a rehabilitation program. The exclusion criteria were the presence of existing cardiovascular disease, lower limb deep vein thrombosis, hypertension or autonomic dysreflexia, ${ }^{17}$ contraindications to ES, serious infection, uncontrolled spasms and unable to understand instructions or provide consent. Written informed consent was obtained as approved by the Medical Ethical Committee of UMMC.

On the basis of the inclusion and exclusion criteria, five spinal-injured patients were initially recruited. Four of them underwent the diagnostic tilt test and three patients were diagnosed with $\mathrm{OH}$. One was diagnosed with very high BPs due to autonomic dysreflexia during the diagnostic tilt test, and was excluded from further study. The autonomic dysreflexia was triggered by the diagnostic tilt test of which no ES was involved.

The ES intervention was deployed to three individuals (subjects A, B and C) who had experienced symptomatic $\mathrm{OH}$. After the first ES intervention, one subject (subject C, T4 American Spinal Injury Association Impairment Scale (AIS) A) decided to withdraw from the study due to poor tolerance of ES sensations.

The two remaining subjects' cases are presented herein to ascertain the effects of ES weekly training on each individual's OH. All assessments and most ES therapy were carried out in Rehabilitation Ward in UMMC, however, some ES training was partially conducted at one subject's residence after discharge. The subjects' characteristics are presented in Table 1.

\section{Study procedure}

A tilt table challenge test is one of the established methods to diagnose the presence of $\mathrm{OH}$ in individuals with SCI. The subject was affixed securely at a head up posture of $60^{\circ}$ for $20 \mathrm{~min}$. SBP and DBP and HR were measured using an automatic blood pressure monitor (Phillips, Amsterdam, The Netherlands)

Table 1 Clinical characteristics of subjects before and after ES

\begin{tabular}{lcc} 
& Subject $A$ & Subject B \\
\hline Age & 62 & 65 \\
Gender & $\mathrm{M}$ & $\mathrm{M}$ \\
Time since injury & 2 weeks & 2 weeks \\
Cause of injury & Metastatic prostate cancer & Traumatic SCI \\
Level of injury & C7 & T9 \\
AIS grade (before Intervention) & AIS B & AIS B \\
AIS grade (after Intervention) & AIS C & AIS B \\
\hline $\begin{array}{l}\text { Abbreviations: AIS, American Spinal Injury Association Impairment Scale; ES, electrical } \\
\text { stimulation; M, male; SCl, spinal cord injury. } \\
\text { Grade of Injury (AIS): B, sensory incomplete; C, sensory and motor incomplete. }\end{array}$
\end{tabular}

every minute. The subjects were tilted back to their supine position when their SBP fell by $20 \mathrm{~mm} \mathrm{Hg}$ or DBP fell by $10 \mathrm{~mm} \mathrm{Hg}$, or when they experienced symptomatic orthostatic intolerance. No medication affecting cardiovascular function such as anticholinergics, antihypertensives and antihypotensives was used by either patient on the days of pre-tests and two post-tests.

The pre-test procedure was similar to one of the diagnostic tilt test. The pretest was conducted on the tilt table without applying ES on the subjects. Thereafter, weekly ES intervention was carried out for 4 weeks.

The ES interventions were conducted $1 \mathrm{~h}$ per day, 4 days per week, for 4 weeks. The electrical stimulator used in this study was RehaStim2 (HASOMED, Magdeburg, Germany). During the ES treatment, self-adhesive gel-backed electrodes were applied on the rectus abdominis, quadriceps, hamstrings and gastrocnemius muscle groups of subjects (Figure 1). The ES parameters applied in this study were frequency: $35 \mathrm{~Hz}$, pulse width: $250 \mu$ s.The current was increased from 0 to maximum tolerable current in five equal steps of current ramp increment in $10 \mathrm{~s}$, and the stimulation current was turned off for the next $10 \mathrm{~s}$, repeatedly. The current amplitude of ES applied was increased from $0 \mathrm{~mA}$ up to the highest current that the subject could tolerate 'pain-free' as the subjects were classified as AIS B and C, and had partial sensation. The maximum current amplitude available for the functional electrical stimulator was $130 \mathrm{~mA}$.

At the end of the 4-week ES intervention phase, two post-tests were conducted on two separate days; without ES and with ES application. The post-test without ES application was conducted before post-test with ES within a minimum of $24 \mathrm{~h}$ duration. The ES parameters used in the post-test with ES such as frequency, pulse width, ramp, period and current amplitude were set to the same parameters as in the last ES intervention session.

\section{Cardiovascular and symptom outcomes}

SBP, DBP, mean arterial pressure (MAP) and HR were obtained during pre-test and post-tests with and without ES-evoked muscle contractions. Symptom Scale Questionnaire for Orthostatic Intolerance was conducted during all tests to measure their $\mathrm{OH}$ symptoms. The questionnaires, with scores from 0 to 10 ( 0 being no symptoms at all and 10 being the worst symptom ever experienced), on $\mathrm{OH}$ symptoms involved questions about dizziness, hearing disturbances, weakness, syncope, pain and palpitations. The injury grade was recorded using the International Standards for Neurological Classification of Spinal Cord Injury for each patient before and after the study.

\section{RESULTS}

\section{Changes in tolerance to stimulation current}

The current amplitude on all four muscle groups (rectus abdominis, quadriceps, hamstrings and gastrocnemius) was gradually increased throughout the 4 weeks of ES therapy. Starting from the 9th ES session, the current amplitude applied on four muscle groups of subject A had to be significantly decreased (Table 2), as he began to feel the triggering of ES stimulation, and he could not withstand ES-induced sensations at high current amplitude. This increased sensibility was observed in parallel to an improvement in the AIS grade as well as neurological level, that is, from C3 AIS B to T7AIS C.

The current amplitude on all four muscle groups of subject B were gradually increased from the first ES session until the eighth ES session (Table 3). The current amplitude applied on rectus abdominis did increase gradually throughout all sessions up to $46 \mathrm{~mA}$ on the eighth ES session, before being reduced gradually back to $28 \mathrm{~mA}$ at the end of week 4 as he could not tolerate the high ES over his abdominal muscles.

\section{Changes in BP, HR and orthostatic symptoms}

Changes in BP, HR and time to $\mathrm{OH}$ are illustrated in Figure 2. Absolute SBP, DBP and MAP data before ES therapy, after ES therapy without concurrent ES and after ES therapy with concurrent ES during $60^{\circ}$ head up tilt are shown in Table 4. On the basis of Symptom Scale Questionnaire for Orthostatic Intolerance, subject A reported fewer 

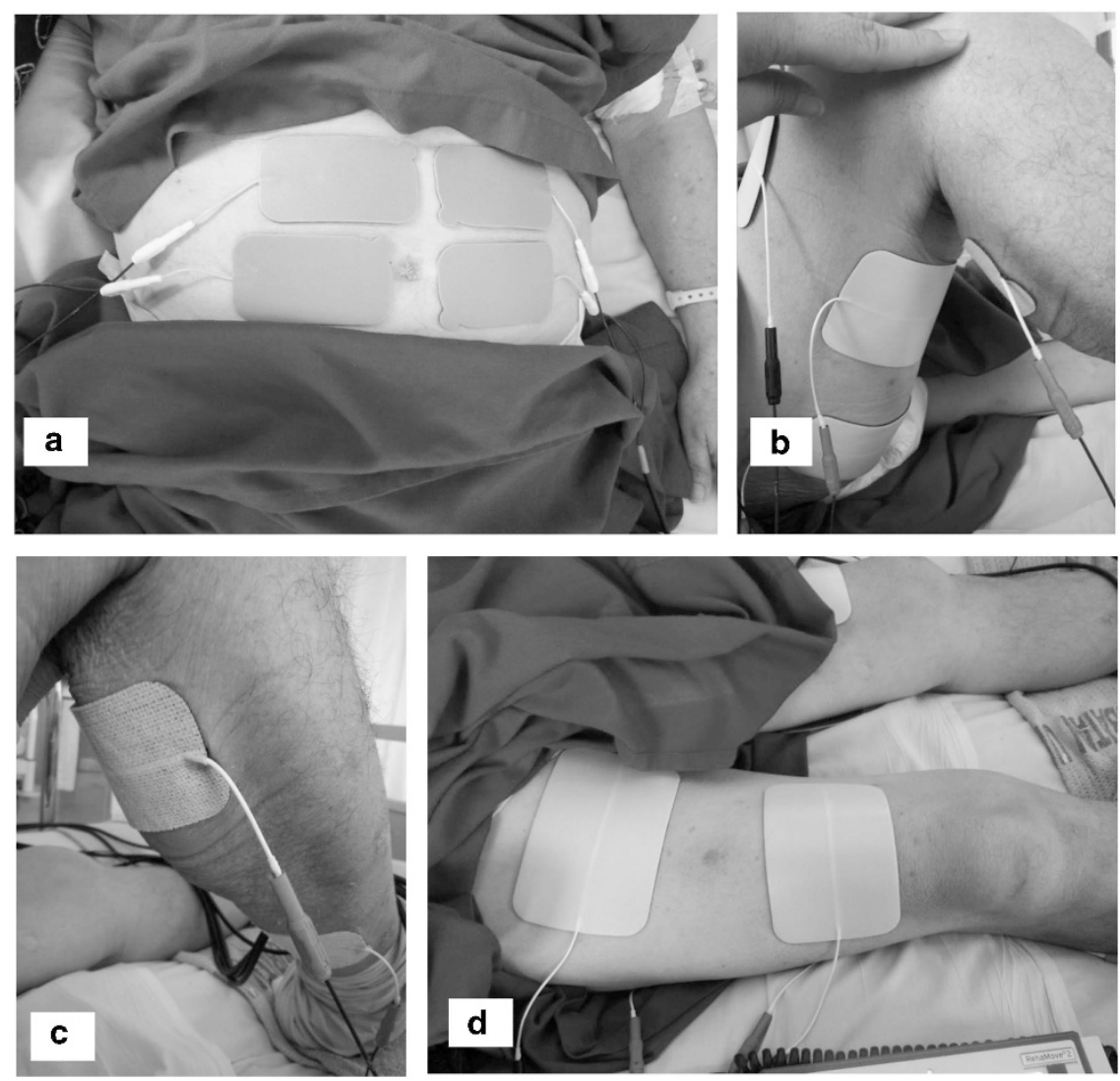

Figure 1 ES applied on (a) rectus abdominis, (b) hamstrings, (c) gastrocnemius and (d) quadriceps muscle group.

Table 2 Current amplitude applied on subject A on each ES session

\begin{tabular}{|c|c|c|c|c|c|c|c|c|c|c|c|c|c|c|c|c|c|c|c|}
\hline \multirow{4}{*}{ Muscle group } & \multicolumn{19}{|c|}{ Current amplitude (mA) for subject $A$} \\
\hline & Week 1 & \multicolumn{4}{|c|}{ Week 2} & \multicolumn{4}{|c|}{ Week 3} & \multicolumn{4}{|c|}{ Week 4} & \multicolumn{4}{|c|}{ Week 5} & \multicolumn{2}{|c|}{ Week 6} \\
\hline & Pre- & Day & Day & Day & Day & Day & Day & Day & Day & Day & Day & Day & Day & Day & Day & Day & Day & $\begin{array}{l}\text { Post-test } \\
\text { (without }\end{array}$ & $\begin{array}{c}\text { Post-test } \\
\text { (with }\end{array}$ \\
\hline & test & 1 & 2 & 3 & 4 & 5 & 6 & 7 & 8 & 9 & 10 & 11 & 12 & 13 & 14 & 15 & 16 & $E S)$ & $E S)$ \\
\hline Quadriceps & - & 18 & 26 & 30 & 34 & 48 & 64 & 74 & 90 & 34 & 36 & 38 & 40 & 42 & 46 & 42 & 36 & - & 36 \\
\hline Hamstrings & - & 20 & 26 & 30 & 34 & 48 & 64 & 74 & 90 & 34 & 36 & 38 & 40 & 42 & 46 & 42 & 36 & - & 36 \\
\hline Gastrocnemius & - & 18 & 24 & 28 & 32 & 40 & 46 & 36 & 38 & 24 & 26 & 28 & 30 & 32 & 36 & 32 & 28 & - & 28 \\
\hline
\end{tabular}

Abbreviation: ES, electrical stimulation.

-, No ES interventions were conducted.

orthostatic symptoms after the intervention, that is, during the post-test with and without ES (pre-test: 6, 5, 7, 3 scores for dizziness, weakness, fainting and pain, respectively, post-test without ES: 5, 4, 5, 0, post-test with ES: 3, 4, 4, 0). In contrast, subject B did not experience any orthostatic symptoms during pre-test, post-test without ES and post-test with ES.

\section{DISCUSSION}

A common pattern in the current clinical case study was the observation that HR was highest when the SBP and the DBP were lowest. This has been commonly attributed to a reduction in venous return and the stroke volume under orthostatic challenge, with a reflex-driven increase in HR to maintain sufficient cardiac output and BPs during head-up tilt. ${ }^{9}$ The pattern observed in our two patients, wherein $\mathrm{HR}$ reached its highest value corresponding to the nadir of $\mathrm{BP}$ suggests that in these sub-acute SCI patients, an intact carotid sinus baroreflex mediated reduced vagal tone in response to orthostasis. ${ }^{6}$

\section{Subject improvement}

Following the definition of $\mathrm{OH}$ during the tilt table challenge originally proposed by Czell, ${ }^{15}$ subject A did not recover from $\mathrm{OH}$ since he could not exceed the 20-min cutoff time based on the 
Table 3 Current amplitude applied on subject B on each ES session

\begin{tabular}{|c|c|c|c|c|c|c|c|c|c|c|c|c|c|c|c|c|c|c|c|}
\hline \multirow{3}{*}{ Muscle group } & \multicolumn{19}{|c|}{ Current amplitude ( $m A$ ) for subject $B$} \\
\hline & \multirow[b]{2}{*}{$\begin{array}{c}\text { Week } 1 \\
\text { Pre- } \\
\text { test }\end{array}$} & \multicolumn{4}{|c|}{ Week 2} & \multicolumn{4}{|c|}{ Week 3} & \multicolumn{4}{|c|}{ Week 4} & \multicolumn{4}{|c|}{ Week 5} & \multicolumn{2}{|c|}{ Week 6} \\
\hline & & $\begin{array}{c}\text { Day } \\
1\end{array}$ & $\begin{array}{c}\text { Day } \\
2\end{array}$ & $\begin{array}{c}\text { Day } \\
3\end{array}$ & $\begin{array}{c}\text { Day } \\
4\end{array}$ & $\begin{array}{c}\text { Day } \\
5\end{array}$ & $\begin{array}{c}\text { Day } \\
6\end{array}$ & $\begin{array}{c}\text { Day } \\
7\end{array}$ & $\begin{array}{c}\text { Day } \\
8\end{array}$ & $\begin{array}{c}\text { Day } \\
9\end{array}$ & $\begin{array}{l}\text { Day } \\
10\end{array}$ & $\begin{array}{c}\text { Day } \\
11\end{array}$ & $\begin{array}{l}\text { Day } \\
12\end{array}$ & $\begin{array}{c}\text { Day } \\
13\end{array}$ & $\begin{array}{c}\text { Day } \\
14\end{array}$ & $\begin{array}{l}\text { Day } \\
15\end{array}$ & $\begin{array}{l}\text { Day } \\
16\end{array}$ & $\begin{array}{c}\text { Post-test } \\
\text { (without } \\
\text { ES) }\end{array}$ & $\begin{array}{c}\text { Post- } \\
\text { test } \\
\text { (with } \\
\text { ES) }\end{array}$ \\
\hline $\begin{array}{l}\text { Rectus } \\
\text { abdominis }\end{array}$ & - & 24 & 24 & 30 & 34 & 40 & 42 & 44 & 46 & 32 & 36 & 36 & 38 & 38 & 24 & 26 & 28 & - & 28 \\
\hline Quadriceps & - & 26 & 26 & 32 & 36 & 62 & 78 & 90 & 100 & 110 & 120 & 130 & 130 & 130 & 130 & 130 & 130 & - & 36 \\
\hline Hamstrings & - & 22 & 22 & 32 & 36 & 62 & 78 & 90 & 100 & 110 & 120 & 130 & 130 & 130 & 130 & 130 & 130 & - & 36 \\
\hline Gastrocnemius & - & 28 & 28 & 30 & 34 & 58 & 62 & 68 & 72 & 82 & 92 & 102 & 112 & 130 & 130 & 130 & 130 & - & 28 \\
\hline
\end{tabular}

Abbreviation: ES, electrical stimulation.

-, No ES interventions were conducted.

a

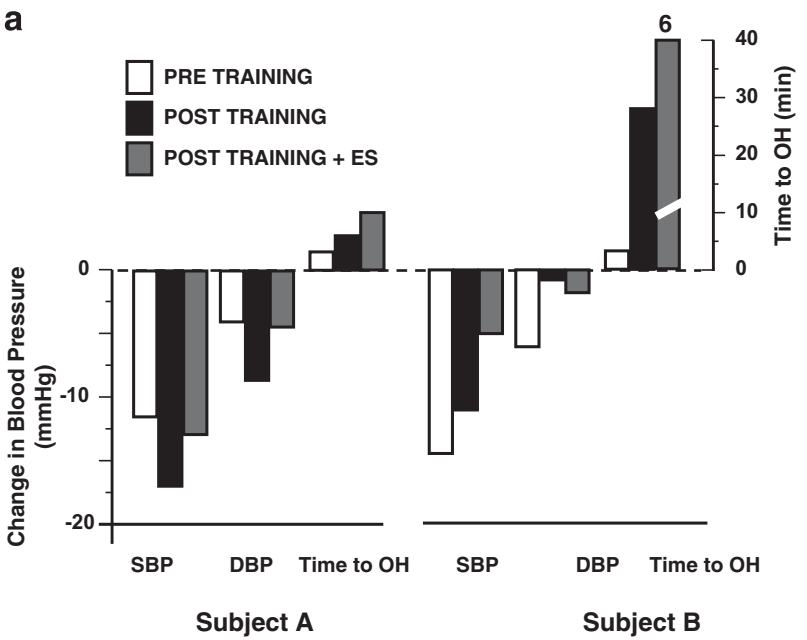

b

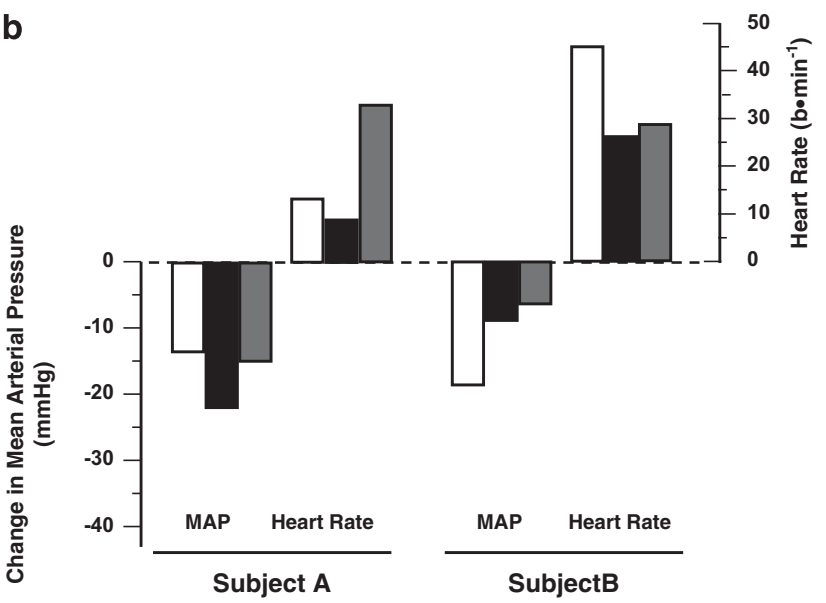

Figure 2 (a) Change in $\mathrm{BP}$ and time to $\mathrm{OH}$ pre- and post-intervention. (b) Change in MAP and HR pre- and post-intervention.

maintenance of normotension. In contrast, subject B fully recovered from $\mathrm{OH}$ after the 4-week ES intervention as demonstrated in the post-training tilt table challenge both with and without concomitant ES-induced muscle contractions.
Two cases-two patterns of improvement

The difference of responses between the two subjects presents a challenge to clinicians for understanding who may or may not benefit from ES therapy during their post-SCI inpatient recovery period. This is because 'natural recovery' and ES tolerance may have been cofactors in both these two sub-acute SCI patients that contributed to the results of this study.

For subject A, who started having greater thoraco-lumbar and lower limb sensations during the third week assessment where he had improved to AIS C from AIS B, the therapists had to reduce the current amplitude applied to the muscle groups used to evoke the ESactivated muscle pump. Sub-optimal current amplitude might have been inadequate to create the vigorous lower-limb contractions necessary to counter a fall of blood pressures during orthostatic challenge. Figure $2 \mathrm{~b}$ clearly illustrated no change in $\mathrm{OH}$ pre- versus post-training, and only a modest effect of combined tilt+ES upon MAP after 4 weeks. Indeed, the ES current amplitude that was deployed during the post-training assessment apparently induced a moderate cardio-acceleration of $\sim 25 \mathrm{~b} \mathrm{~min}^{-1}$. These factors of orthostatic response against a background of natural post-SCI recovery were possible factors for subject A not recovering from $\mathrm{OH}$, with only a modest duration to clinical manifestation during $60^{\circ}$ head-up tilt (Figure 2a).

In contrast, subject B presented with a more 'classical' response to head up tilt of $60^{\circ}$ after intervention. With the ability to tolerate higher current amplitudes (up to $130 \mathrm{~mA}$ across hamstrings and gastrocnemius), thereby evoking more vigorous muscle contractions in his legs over 4 weeks of ES therapy, $\mathrm{OH}$ was clinically reduced-decreased MAP was halved from pre- to post-training tilt challenge, and it was further improved during combined tilt+ES (Figure 2b). Consequently, orthostatic-induced cardio-acceleration was also diminished by $\sim 19$ $\mathrm{b}$ min $^{-1}$ with a significant increase in symptom-free heads up tilting beyond $20 \mathrm{~min}$ under both post-training conditions.

Clearly, the inability to tolerate sufficiently high current amplitudes for potentially beneficial effects of the ES therapy is one of the limitations of this rehabilitation approach, as evidently demonstrated by subject A whose lower tolerance to ES blunted any anti-hypotensive effects that it might have had over 4 weeks of treatment. This could be addressed by stimulating the common peroneal nerve, which would require lower stimulation current level due to the effective nerve stimulation of smaller muscle groups. Stimulating the common peroneal nerves, thus producing the critical movement of cyclical 
Table 4 Blood pressure responses during $60^{\circ}$ head up tilt

\begin{tabular}{|c|c|c|c|c|c|c|c|c|c|}
\hline & \multicolumn{3}{|c|}{ Before ES therapy } & \multicolumn{3}{|c|}{ After ES therapy (no concurrent ES) } & \multicolumn{3}{|c|}{ After ES therapy (with concurrent ES) } \\
\hline & $\begin{array}{c}\text { Initial } \\
\text { (mm Hg) }\end{array}$ & $\begin{array}{l}60^{\circ} \text { Head up } \\
\text { tilt }(\mathrm{mm} \mathrm{Hg})\end{array}$ & $\begin{array}{l}\text { Time to } \mathrm{OH} \\
\text { onset (min) }\end{array}$ & $\begin{array}{c}\text { Initial } \\
\text { (mm Hg) }\end{array}$ & $\begin{array}{l}60^{\circ} \text { Head up } \\
\text { tilt }(\mathrm{mm} \mathrm{Hg})\end{array}$ & $\begin{array}{l}\text { Time to } \mathrm{OH} \\
\text { onset (min) }\end{array}$ & $\begin{array}{c}\text { Initial } \\
\text { (mm Hg) }\end{array}$ & $\begin{array}{l}60^{\circ} \text { Head up } \\
\text { tilt }(\mathrm{mm} \mathrm{Hg})\end{array}$ & $\begin{array}{l}\text { Time to } \mathrm{OH} \\
\text { onset (min) }\end{array}$ \\
\hline Subject $A$ & 123/95 (104) & 102/81 (88) & 4 & 147/92 (110) & $113 / 75(88)$ & 6 & 115/71 (86) & $89 / 62(71)$ & 10 \\
\hline Subject B & 127/82 (97) & 106/70 (82) & 4 & 122/72 (89) & 100/71 (81) & 28 & 124/77 (93) & 105/71 (82) & 60 \\
\hline
\end{tabular}

Abbreviations: ES, electrical stimulation; $\mathrm{OH}$, orthostatic hypotension.

Note: 'Initial' denotes supine blood pressures before $60^{\circ}$ head up tilt. ' $60^{\circ}$ head up tilt' denotes final blood pressures during $\mathrm{OH}$ before tilt challenge termination. 'Time to $\mathrm{OH}$ ' denotes time until clinical appearance of $\mathrm{OH}$. Data are systolic blood pressure/diastolic blood pressure (mean blood pressure) and time (minutes).

ankle dorsiflexion might also result in greater blood flow effect, which would be an interesting outcome to be determined in future studies.

\section{CONCLUSION}

This study highlighted some positive effects of regular ES training in individuals with sub-acute SCI for managing their $\mathrm{OH}$. A limiting factor is likely poor or reduced tolerance to ES stimulation current, which restricts the quality of ES-evoked muscle contractions deployed to reduce venous pooling and hypotension in upright postures. However, for individuals who can tolerate moderate-to-vigorous ESinduced contractions during their inpatient rehabilitation, a longer duration to clinically manifest $\mathrm{OH}$, reduced symptoms and improved blood pressure responses can be observed. A longer intervention duration and follow-up time would enable further investigation about the effectiveness of ES in managing $\mathrm{OH}$ in this patient population.

\section{DATA ARCHIVING}

There were no data to deposit.

\section{CONFLICT OF INTEREST}

The authors declare no conflict of interest.

\section{ACKNOWLEDGEMENTS}

We thank Ms T Noor Rabihah T Mahamed for help with edits and referencing. This research was fully supported by the Ministry of Higher Education, Malaysia and University of Malaya through High Impact Research (HIR) Grant No. UM.C/625/1/HIR/MOHE/ENG/39.

1 Guyenet PG. The sympathetic control of blood pressure. Nat Rev Neurosci 2006; 7: 335-346.

2 Chao $\mathrm{CY}$, Cheing GL. Orthostatic hypotension for people with spinal cord injuries. Hong Kong Physiother J 2008; 26: 51-58.
3 Claydon VE, Steeves JD, Krassioukov A. Orthostatic hypotension following spinal cord injury: understanding clinical pathophysiology. Spinal Cord 2006; 44: 341-351.

4 Illman A, Stiller K, Williams M. The prevalence of orthostatic hypotension during physiotherapy treatment in patients with an acute spinal cord injury. Spinal Cord 2000; 38: 741-747.

5 Raymond J, Davis GM, Bryant G, Clarke J. Cardiovascular responses to an orthostatic challenge and electrical-stimulation-induced leg muscle contractions in individuals with paraplegia. Eur J Appl Physiol Occup Physiol 1999; 80: 205-212.

6 Raymond J, Davis GM, van der Plas MN, Groeller H, Simcox S. Carotid baroreflex control of heart rate and blood pressure during ES leg cycling in paraplegics. J Appl Physiol 2000; 88: 957-965

7 Sampson EE, Burnham RS, Andrews BJ. Functional electrical stimulation effect on orthostatic hypotension after spinal cord injury. Arch Phys Med Rehabil 2000; 81: 139-143.

8 Demchak TJ, Linderman JK, Mysiw WJ, Jackson R, Suun J, Devor ST. Effects of functional electric stimulation cycle ergometry training on lower limb musculature in acute SCI individuals. J Sports Sci Med 2005; 4: 263-271.

9 Chao CY, Cheing GL. The effects of lower-extremity functional electric stimulation on the orthostatic responses of people with tetraplegia. Arch Phys Med Rehabil 2005; 86: 1427-1433.

10 Taylor PN, Tromans AM, Harris KR, Swain ID. Electrical stimulation of abdominal muscles for control of blood pressure and augmentation of cough in a C3/4 level tetraplegic. Spinal Cord 2002; 40: 34-36.

11 Faghri PD, Yount J. Electrically induced and voluntary activation of physiologic muscle pump: a comparison between spinal cord-injured and able-bodied individuals. Clin Rehabil 2002; 16: 878-885.

12 Yoshida T, Masani K, Sayenko DG, Miyatani M, Fisher JA, Popovic MR. Cardiovascular response of individuals with spinal cord injury to dynamic functional electrical stimulation under orthostatic stress. IEEE Trans Neural Syst Rehabil Eng 2013; 21: 37-46.

13 Elokda AS, Nielsen DH, Shields RK. Effect of functional neuromuscular stimulation on postural related orthostatic stress in individuals with acute spinal cord injury. J Rehabil Res Dev37: 535-542.

14 Chi L, Masani K, Miyatani M, Thrasher TA, Johnston KW, Mardimae A et al. Cardiovascular response to functional electrical stimulation and dynamic tilt table therapy to improve orthostatic tolerance. J Electromyogr Kinesiol 2008; 18: 900-907.

15 Czell D, Schreier R, Rupp R, Eberhard S, Colombo G, Dietz V. Influence of passive leg movements on blood circulation on the tilt table in healthy adults. J Neuroeng Rehabil 2004; $1: 4$.

16 Schatz IJ, Bannister R, Freeman RL, Goetz CG, Jankovic J, Kaufmann HC et al. Consensus statement on the definition of orthostatic hypotension, pure autonomic failure, and multiple system atrophy. Neurology 1996; 46: 1470.

17 Krenz NR, Meakin SO, Krassioukov AV, Weaver LC. Neutralizing intraspinal nerve growth factor blocks autonomic dysreflexia caused by spinal cord injury. J Neurosci 1999; 19: 7405-7414. 